\title{
Age, pattern of consultation, and functional disability in elderly patients in one general practice
}

\author{
R G P Hall, D M Channing
}

\begin{abstract}
Objective-To examine how functional disability varies with sex, age, and other variables in patients aged 75 and over living in the community and to ascertain whether a statistical model derived from the variables in this population usefully predicted functional disability in another of similar age.

Design-Retrospective study of data collected by interview and by examination of medical records.

Setting-An urban general practice with five partners and a list of 15000 patients, very few of whom belonged to ethnic minorities.

Patients - 775 Patients (252 men, 523 women) aged 75 and over living in the community between September 1985 and August 1986; 13 other patients considered to be unsuitable and 14 who declined an interview were excluded. Also 94 patients who became 75 or joined the practice after August 1986.

Main outcome measure-The proportions of fit, partially disabled, and severely disabled (housebound) patients.
\end{abstract}

Results-90 Men (35.7\%) and 128 women (24.5\%) were fit, and 27 men $(10 \cdot 7 \%)$ and 116 women $(22 \cdot 2 \%)$ were housebound; in all age groups women were significantly more likely to be disabled than men. A significant trend towards greater disability was shown with increasing age and, more noticeably, with pattern of consultation when patients were divided into three categories based on the number of times they had attended the surgery and been visited at home over about two years. Statistical models gave the forecast percentage of fit and severely disabled patients for each sex, age group, and pattern of consultation, and a simple scheme was derived to identify from information wholly contained in medical records most of those patients most prone to severe disability. The scheme was verified by applying it to a population of 94 elderly patients in 1988-9.

Conclusion-Sex, age, and pattern of consultation together provide a quick indication of elderly patients' tendency to severe disability, which can help in screening and in day to day consultations.

Norton Medical Centre, Norton, Stockton on Tees, Cleveland TS20 1AN R G P Hall, MRCP, general practitioner D M Channing, DPHIL, research assistant

Correspondence to: Dr Hail.

\section{Introduction}

The white paper Promoting Better Health encouraged family doctors to provide comprehensive medical care for the elderly, ${ }^{1}$ and changes in their contract require them to review patients aged 75 years and over each year. ${ }^{2}$ Preventive health care for the elderly has been under continuous review since Williamson et al's paper in 1964 reported unmet need. ${ }^{3}$ Studies have shown, however, that the over $75 \mathrm{~s}$ are generally active, independent, and optimistic in outlook. ${ }^{4}$ Those mostly healthy. ${ }^{5-7}$ This independence in the elderly should obviously be encouraged. To avoid emphasising the negative aspects of aging, surveillance should be who do not consult their general practitioner are non-intrusive and help offered only when it is needed. Any guidelines suggesting when that point has been reached are likely to be of value.

\section{Patients and methods}

Our primary health care team in urban north east England serves 15000 patients, whose social class distribution approximates to the national average. There are no sizable ethnic minorities. The practice has computerised data and A4 records. At the time of the study there were five partners.

In 1985-6 two care visitors for the elderly surveyed 775 patients aged 75 and over living in the community. The survey's main aim was to improve the overall care of these patients, where needed, by extra visiting and by initiating the provision of extra services by statutory, voluntary, and charitable organisations. This report concerns a subsidiary aim - to examine how functional disability varied with sex, age, and other criteria with a view to seeking an index of the likelihood of severe disability.

The sampling frame was the age-sex register of the practice in July 1985 . Of the 1046 patients aged 75 or more, 71 were in part III accommodation, 147 were in private residential and nursing homes, 12 had left the practice area, 14 had died, 13 were considered by their doctor to be unsuitable for inclusion (these-included the terminally ill), and 14 declined an interview; thus 775 patients were included in the survey. Each elderly patient was interviewed at home between September 1985 and August 1986 by a care visitor for the elderly, who completed a standard survey form, partly during the interview and partly by abstracting data from the patient's medical record. Among many items recorded were birth date and the number of times the patient had attended the surgery and the number of times a doctor had visited the patient at home since 1 January 1984. The date of the interview was not recorded, so the patient's age at interview was known only to within one year. The period for which the number of consultations was recorded was $2 \cdot 25$ years (range $1 \cdot 75-2 \cdot 75$ ).

Four categories of functional disability were used, which were based on the King's Fund register ${ }^{8}$ and were similar to those used in other studies ${ }^{910}$ : fit and active, lifestyle appreciably disturbed by disability but not housebound, lifestyle severely modified by disability (housebound), and bedfast. As only two patients (both men) were bedfast the last two categories were combined to give three groups, designated fit, partially disabled, and housebound.

The relations between disability and sex and between disability and age for both sexes were examined statistically by the $\chi^{2}$ test for trend. ${ }^{11}$ Logistic regressions (see below) were then used to derive equations for the proportion of housebound and fit patients according to sex and age; to reduce random fluctuation 
a three age moving total of numbers of patients was used, starting at age 75 with a two age total for ages 75 and 76. Ninety five per cent confidence intervals were calculated for the forecasts given by the regression equations.

Numbers and types of consultations (attendances at the surgery and home visits) were grouped in a simple way to divide patients into three categories corresponding to a decreasing proportion of fit patients and an increasing proportion of housebound patients (see fig 2 and table V). The significance of the relation was tested with the $\chi^{2}$ test for trend. Other possible indicators of functional disability were sought and tested in a similar way-namely, numbers of admissions to hospital and outpatient attendances; numbers of items on repeat prescription (both in total and taking account of psychotropic, diuretic, and non-steroidal antiinflammatory drugs separately); and numbers of serious ailments. The three consultation categories were used in further logistic regressions of the proportions of housebound and fit patients with sex and age. From the resulting equations the forecast proportions of housebound and fit men and women in each consultation category at each age were calculated, with $95 \%$ confidence intervals.

\section{DETAILS OF LOGISTIC REGRESSIONS ${ }^{11}$}

Logistic regression is a method of studying the variation in a binary distribution. The formula used for the logit transformation was $\ln ((\mathrm{r}+0.5) /(\mathrm{n}-\mathrm{r}+0 \cdot 5))$, where $r$ was the number of housebound or fit patients among the total $\mathrm{n}$ at each stage; this formula permitted cases were $r=0$ or $n$ and also reduced bias for small values of $n$. Empirical weights were used. The age used in the regression was age in years minus 74 .

The regressions gave the following equations for the proportions of housebound and fit patients according to sex and age:

Housebound: logit $=-2 \cdot 354-0 \cdot 639 \mathrm{M}+0 \cdot 152($ age -74$)$ $\left(\mathrm{R}^{2}=0 \cdot 887\right)$

Fit: logit $=-0.526+0 \cdot 493 \mathrm{M}-0.095($ age -74$)$

$$
\left(\mathrm{R}^{2}=0 \cdot 804\right)
$$

where $M$ (a dummy variable) was 1 for men and 0 for women. $R^{2}$ was the fraction of the variance accounted for by the regression equation. All constants and coefficients were significant $(p<0 \cdot 001)$. Forecast logits were transformed back to proportions by calculating $\exp (\operatorname{logit}) /(1+\exp (\operatorname{logit}))$.

When the three consultation categories were introduced logistic regression with age using consultation category 2 as the norm and consultation categories 1 and $3(\mathrm{Cl}$ and $\mathrm{C} 3$ ) as dummy variables gave the following equations:

Housebound: logit $=-2 \cdot 300-0 \cdot 337 \mathrm{M}+0 \cdot 100$

$($ age -74$)-0.820 \mathrm{Cl}+1 \cdot 607 \mathrm{C} 3 \quad\left(\mathrm{R}^{2}=0 \cdot 872\right)$

Fit: logit $=-1 \cdot 005+0 \cdot 394 \mathrm{M}-0 \cdot 052($ age -74$)+$

$$
0 \cdot 883 \mathrm{Cl}-0.891 \mathrm{C} 3 \quad\left(\mathrm{R}^{2}=0 \cdot 810\right)
$$

where $\mathrm{Cl}$ and $\mathrm{C} 3$ were 1 for consultation categories 1 and 3 respectively and 0 otherwise. All constants and coefficients were significant $(p<0 \cdot 002)$.

\begin{tabular}{|c|c|c|c|c|c|c|c|c|}
\hline \multirow{2}{*}{$\begin{array}{c}\text { Age } \\
\text { (years) }\end{array}$} & \multicolumn{4}{|c|}{ Men } & \multicolumn{4}{|c|}{ Women } \\
\hline & Fit & Partially disabled & Housebound & Total & Fit & Partially disabled & Housebound & Total \\
\hline $75-79$ & $58(41)$ & $73(51)$ & $12(8)$ & $143(100)$ & $86(32)$ & $145(54)$ & $37(14)$ & $268(100)$ \\
\hline $80-84$ & $24(31)$ & $45(58)$ & $8(10)$ & $77(100)$ & $30(20)$ & $87(58)$ & $32(22)$ & $149(100)$ \\
\hline$\geqslant 85$ & $8(25)$ & $17(53)$ & $7(22)$ & $32(100)$ & $12(11)$ & $47(44)$ & $47(44)$ & $106(100)$ \\
\hline Total & $90(36)$ & $135(54)$ & $27(11)$ & $252(100)$ & $128(25)$ & $279(53)$ & $116(22)$ & $523(100)$ \\
\hline
\end{tabular}

TABLE I-Distribution of functional disability by sex and age. Figures are numbers (percentages) of patients

Disability trend with sex: for age $75-79 \chi^{2}=4.32(p<0.05)$; for age $80-84 \chi^{2}=6.03(p<0.02)$; for age $\geqslant 85 \chi^{2}=6.75$ $(\mathrm{p}<0.01)$; for all ages $\chi^{2}=19 \cdot 76(\mathrm{p}<0.001)$.

Disability trend with age: for men $\chi^{2}=5.87(\mathrm{p}<0.02)$; for women $\chi^{2}=42.71(\mathrm{p}<0.001)$; for both sexes $\chi^{2}=50.91$ Disability
$(\mathrm{p}<0.001)$
TABLE II - Ninety five per cent confidence intervals for mean forecasts of regression equations of percentages of housebound and fit patients with sex and age

\begin{tabular}{ccccrr}
\hline & \multicolumn{2}{c}{ Men } & & \multicolumn{2}{c}{ Women } \\
\cline { 2 - 3 } \cline { 5 - 6 } (years) & Housebound & Fit & & Housebound & Fit \\
\hline 75 & $4 \cdot 9$ to $6 \cdot 2$ & $44 \cdot 8$ to $48 \cdot 8$ & & $9 \cdot 0$ to $11 \cdot 0$ & $33 \cdot 2$ to $36 \cdot 7$ \\
80 & $10 \cdot 1$ to $12 \cdot 2$ & $33 \cdot 6$ to $37 \cdot 1$ & & $17 \cdot 7$ to $20 \cdot 7$ & $23 \cdot 6$ to $26 \cdot 4$ \\
85 & $19 \cdot 3$ to $23 \cdot 0$ & $23 \cdot 8$ to $26 \cdot 9$ & & $31 \cdot 5$ to $35 \cdot 8$ & $16 \cdot 0$ to $18 \cdot 3$ \\
90 & $33 \cdot 5$ to $39 \cdot 4$ & $16 \cdot 0$ to $18 \cdot 8$ & & $49 \cdot 3$ to $54 \cdot 8$ & $10 \cdot 5$ to $12 \cdot 4$ \\
95 & \multicolumn{2}{c}{ Insufficient data } & & $67 \cdot 0$ to $72 \cdot 6$ & $6 \cdot 6$ to $8 \cdot 2$ \\
\hline
\end{tabular}

No
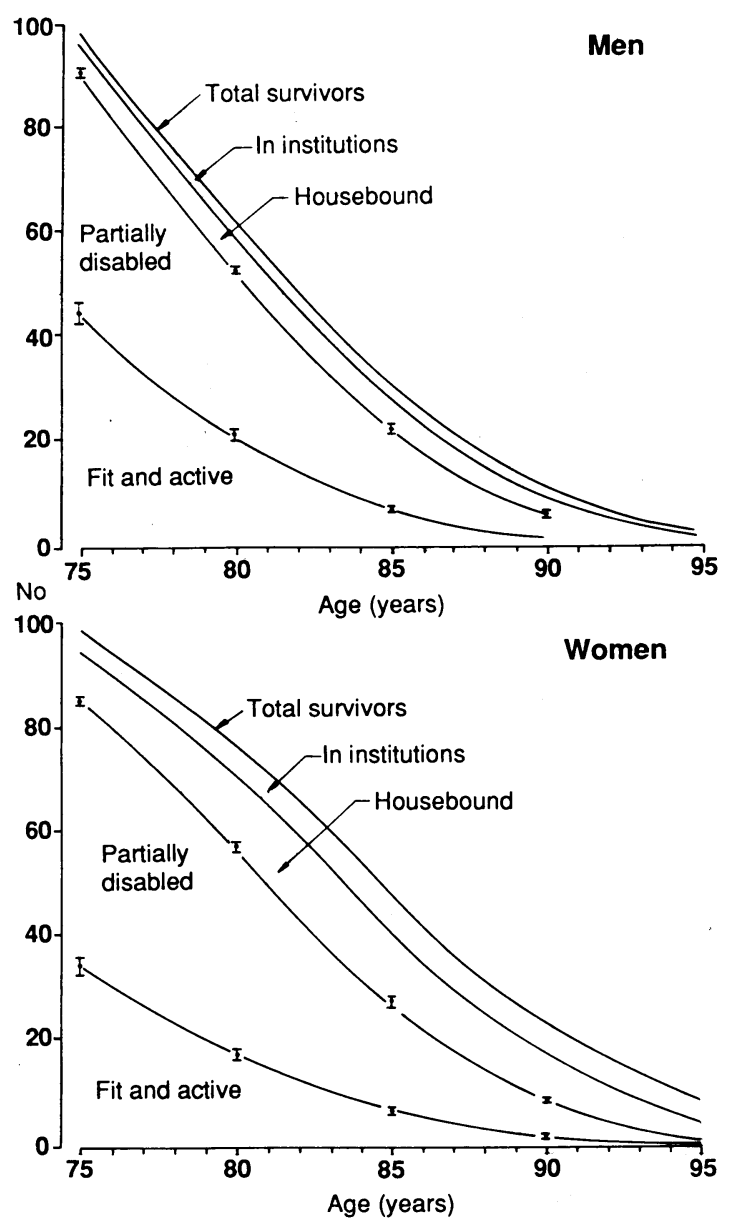

FIG 1 -Forecast survival of 100 men and 100 women from age 75 by functional ability. Vertical bars represent $95 \%$ confidence intervals

These regressions, and the calculation of confidence intervals for forecast values, were done on an Acorn Archimedes microcomputer with the FIRST statistical package.

\section{Results}

A significant trend towards greater disability was shown for women and for both sexes with increasing age, the relation being stronger for women than for men (table I). Logistic regression of the proportions of housebound and fit patients with sex and age yielded $95 \%$ confidence intervals for the mean forecasts of the regression equations (table II) (see table VI for the rounded forecast mean values for the pecentage housebound for each sex and age).

The distributions of age and sex among our elderly patients were similar to those in the United Kingdom as a whole in 1984 (table III). ${ }^{12}$ In 1986 forecasts, based on life expectancy tables, of the number of survivors at successive ages from 100 men and 100 women initially aged 65 were published. ${ }^{12}$ We used those figures, together with our results, in diagrams of the approximate forecast proportions of fit, partially disabled, and 
housebound survivors at successive ages from 100 men and 100 women initially aged 75 (fig 1 ).

Table IV shows that women consulted more than men $(p<0.001)$ and that the proportion of patients who had not consulted was slightly smaller among women than men $(p<0 \cdot 1)$. Of the 32 men who had not consulted, 17 were fit, 14 partially disabled, and one housebound. Of the 45 women who had not consulted, 21 were fit, 18 partially disabled, and six housebound. One hundred and twenty five patients $(16 \cdot 1 \%)$ accounted for half of the attendances; 65 of the patients $(8 \cdot 4 \%)$ accounted for half of the visits. With increasing age attendances tended to fall and visits to increase; the total number of consultations remained much the same but increased sharply for patients aged over 90 .

The three consultation categories into which patients were divided (fig 2) showed a highly significant trend towards increased disability (table V). The other possible indicators examined (numbers of hospital visits, repeat prescriptions, and serious ailments) showed less significant trends. Logistic regression for the proportions of housebound and fit patients with sex, age, and consultation category gave $95 \%$ confidence intervals exemplified by the following for the forecast mean percentages of housebound patients: among men aged 75 years in consultation category $1-2 \cdot 8 \%$ to $4 \cdot 0 \%$, in category $2-6 \cdot 3 \%$ to $8 \cdot 5 \%$, in category $3-25 \cdot 1 \%$ to $31 \cdot 6 \%$; among men aged 90 years $11 \cdot 4 \%$ to $15 \cdot 9 \%, 22 \cdot 8 \%$ to $29 \cdot 8 \%$, and $59 \cdot 8 \%$ to $67 \cdot 7 \%$ respectively; among women aged 75 years $4 \cdot 0 \%$ to

TABLE III-Distributions of elderly patients by age and sex in Norton Medical Centre and United Kingdom. ${ }^{12}$ (Figures for numbers of patients in United Kingdom are millions)

\begin{tabular}{|c|c|c|c|c|c|c|}
\hline & \multicolumn{3}{|c|}{ No aged: } & \multirow{2}{*}{$\begin{array}{l}\text { Patients aged } 75-84 \\
\text { as } \% \text { of total } \\
\text { aged } \geqslant 75\end{array}$} & \multirow{2}{*}{$\begin{array}{l}\text { Men as \% of } \\
\text { total aged } \\
75-84\end{array}$} & \multirow{2}{*}{$\begin{array}{c}\text { Men as } \% \text { o } \\
\text { total aged } \\
\geqslant 85\end{array}$} \\
\hline & $75-84$ & $\geqslant 85$ & $\geqslant 75$ & & & \\
\hline \multicolumn{7}{|c|}{ United Kingdom: } \\
\hline Men & $1 \cdot 0$ & $0 \cdot 2$ & $1 \cdot 2]$ & & & \\
\hline Women & 1.9 & 0.5 & $2 \cdot 4\}$ & 81 & 34 & 29 \\
\hline All & $2 \cdot 9$ & 0.7 & $3 \cdot 6$ & & & \\
\hline \multicolumn{7}{|c|}{ Norton Medical Centre: } \\
\hline Men & 311 & 47 & 358 & & & \\
\hline Women & 547 & 141 & $688\}$ & 82 & 36 & 25 \\
\hline All & 858 & 188 & 1046 & & & \\
\hline \multicolumn{7}{|c|}{ Study sample: } \\
\hline Men & 220 & 32 & 252] & & & \\
\hline Women & 417 & 106 & $523\}$ & 82 & 35 & 23 \\
\hline All & 637 & 138 & 775 & & & \\
\hline
\end{tabular}

TABLE IV-Distribution of consultations (excluding telephone consultations). Figures are numbers (percentages) of patients

\begin{tabular}{|c|c|c|c|c|c|c|}
\hline \multirow{2}{*}{$\begin{array}{c}\text { No of } \\
\text { consultations } \\
\text { in } 2 \cdot 25 \text { years }\end{array}$} & \multicolumn{3}{|c|}{ Men } & \multicolumn{3}{|c|}{ Women } \\
\hline & Attendances & Visits & Total & Attendances & Visits & Total \\
\hline 0 & $53(21 \cdot 0)$ & $135(53 \cdot 6)$ & $32(12 \cdot 7)$ & $129(24 \cdot 7)$ & $221(42 \cdot 3)$ & $45(8 \cdot 6)$ \\
\hline 1 - & $97(38 \cdot 5)$ & $74(29 \cdot 4)$ & $78(31.0)$ & $174(33 \cdot 3)$ & $179(34 \cdot 2)$ & $135(25 \cdot 8)$ \\
\hline $5-$ & $64(25 \cdot 4)$ & $23(9 \cdot 1)$ & $61(24 \cdot 2)$ & $120(22.9)$ & $55(10 \cdot 5)$ & $134(25 \cdot 6)$ \\
\hline $10-$ & $28(11 \cdot 1)$ & $13(5 \cdot 2)$ & $47(18 \cdot 7)$ & $57(10 \cdot 9)$ & $28(5 \cdot 4)$ & $108(20 \cdot 7)$ \\
\hline $15-$ & $6(2 \cdot 4)$ & $4(1 \cdot 6)$ & $21(8 \cdot 3)$ & $24(4 \cdot 6)$ & $18 \quad(3 \cdot 4)$ & $34(6 \cdot 5)$ \\
\hline $20-$ & $2(0 \cdot 8)$ & $2(0 \cdot 8)$ & $10(4 \cdot 0)$ & $15(2.9)$ & $11(2 \cdot 1)$ & $41 \quad(7 \cdot 8)$ \\
\hline$\geqslant 30$ & $2(0 \cdot 8)$ & $1(0.4)$ & $3(1 \cdot 2)$ & $4(0 \cdot 8)$ & $11(2 \cdot 1)$ & $26(5 \cdot 0)$ \\
\hline Total & $252(100)$ & $252(100)$ & $252(100)$ & $523(100)$ & $523(100)$ & $523(100)$ \\
\hline $\begin{array}{l}\text { Consultations/ } \\
100 \text { patients/year }\end{array}$ & 214 & 105 & 319 & 239 & 174 & 413 \\
\hline
\end{tabular}

$5 \cdot 4 \%, 8 \cdot 7 \%$ to $11 \cdot 4 \%$, and $32 \cdot 5 \%$ to $38 \cdot 8 \%$; and among women aged 90 years $15 \cdot 6 \%$ to $20 \cdot 5 \%, 29 \cdot 7 \%$ to $36 \cdot 7 \%$, and $68 \cdot 2 \%$ to $74 \cdot 0 \%$. Table VI shows the rounded forecast mean percentages of housebound patients for all combinations of sex, age, and consultation category.

We examined the possible use of these results as a preliminary screening aid for functional disability. Patients could be selected for further assessment of functional disability if the forecast percentage of housebound patients of their sex, age, and consultation category (table VI) exceeded a chosen threshold figure; we selected $10 \%$ because this gave an acceptable compromise between sensitivity and specificity. When applied to the study sample this scheme captured 129 of the 143 housebound patients and rejected 162 of the 218 fit patients, a sensitivity of $90 \%$ and a specificity of $74 \%$. It captured $52 \%$ (401) of all patients. The scheme was subsequently tested in 1988-9 on a further sample of 94 patients ( 36 men and 58 women) who had become 75 or had entered the practice since the end of the original survey. As the numbers of consultations with these patients were abstracted for only the 12 months before interview the critical value for attendances plus visits was reduced from eight (in two years) to four (in one year) for determining the consultation category. Again with a $10 \%$ threshold, the method correctly identified 36 of the 40 fit patients and six of the eight housebound patients.

\section{Discussion}

As expected from national figures, our patients aged 75 and over comprised twice as many women (523) as men (252); this ratio increased with advancing age. Moreover, there were four times as many housebound women (116) as housebound men (27). The ratio of fit to housebound patients was 3.3 for men $(90: 27)$ but only $1 \cdot 1$ for women (128:116), and the ratio was higher in men than women in all age groups, indicating that though many more women than men survive to advanced age in the community, they do so at the expense of a higher rate of disability. For both sexes disability was significantly related to age, the relation being stronger for women than men (table I). As our sample had a similar age-sex distribution to that of the United Kingdom, and assuming it to be representative in its proportions of disabled people living in the community, we used our results in conjuction with published figures ${ }^{12}$ to construct graphs of the approximate forecast proportions of fit, partially disabled, and housebound patients among survivors of 100 men and 100 women initially aged 75 (fig 1). Because the national ratio of men aged 75 to women aged 75 is about $3: 4$ the figures in the graph for men would require scaling down for a composite picture.

As in comparable studies, we found that most people aged 75 and over living in the community consult their general practitioners (table IV). In roughly two and a quarter years $77 \%(593)$ had attended the surgery and $54 \%$ (419) had received home visits; 90\% (698) had consulted in one or both of these ways. On average women had consulted more than men. Most of the $10 \%$ (77) who had not consulted at all were found to be in

TABLE V-Distribution of functional disability by consultation category (see fig 2). Figures are numbers (percentages) of patients

\begin{tabular}{|c|c|c|c|c|c|c|c|c|}
\hline \multirow[b]{2}{*}{$\begin{array}{l}\text { Consultation } \\
\text { category }\end{array}$} & \multicolumn{4}{|c|}{ Men } & \multicolumn{4}{|c|}{ Women } \\
\hline & Fit & $\begin{array}{l}\text { Partially } \\
\text { disabled }\end{array}$ & Housebound & Total & Fit & $\begin{array}{l}\text { Partially } \\
\text { disabled }\end{array}$ & Housebound & Total \\
\hline 1 & $69(51)$ & $63(47)$ & $3(2)$ & $135(100)$ & $87(39)$ & $121(55)$ & $13(6)$ & $221(100)$ \\
\hline 2 & $20(26)$ & $48(63)$ & 8 (11) & $76(100)$ & $30(19)$ & $105(67)$ & 22 (14) & $157(100)$ \\
\hline 3 & $1(2)$ & $24(59)$ & $16(39)$ & $41(100)$ & $11(8)$ & $53(37)$ & $81(56)$ & $145(100)$ \\
\hline Total & $90(36)$ & $135(54)$ & $27(11)$ & $252(100)$ & $128(24)$ & $279(53)$ & $116(22)$ & $523(100)$ \\
\hline
\end{tabular}

Disability trend with consultation type: for men $\chi^{2}=58.39(p<0.001)$; for women $\chi^{2}=122.34(p<0.001)$; for both sexes $\chi^{2}=188.79(p<0.001)$. 


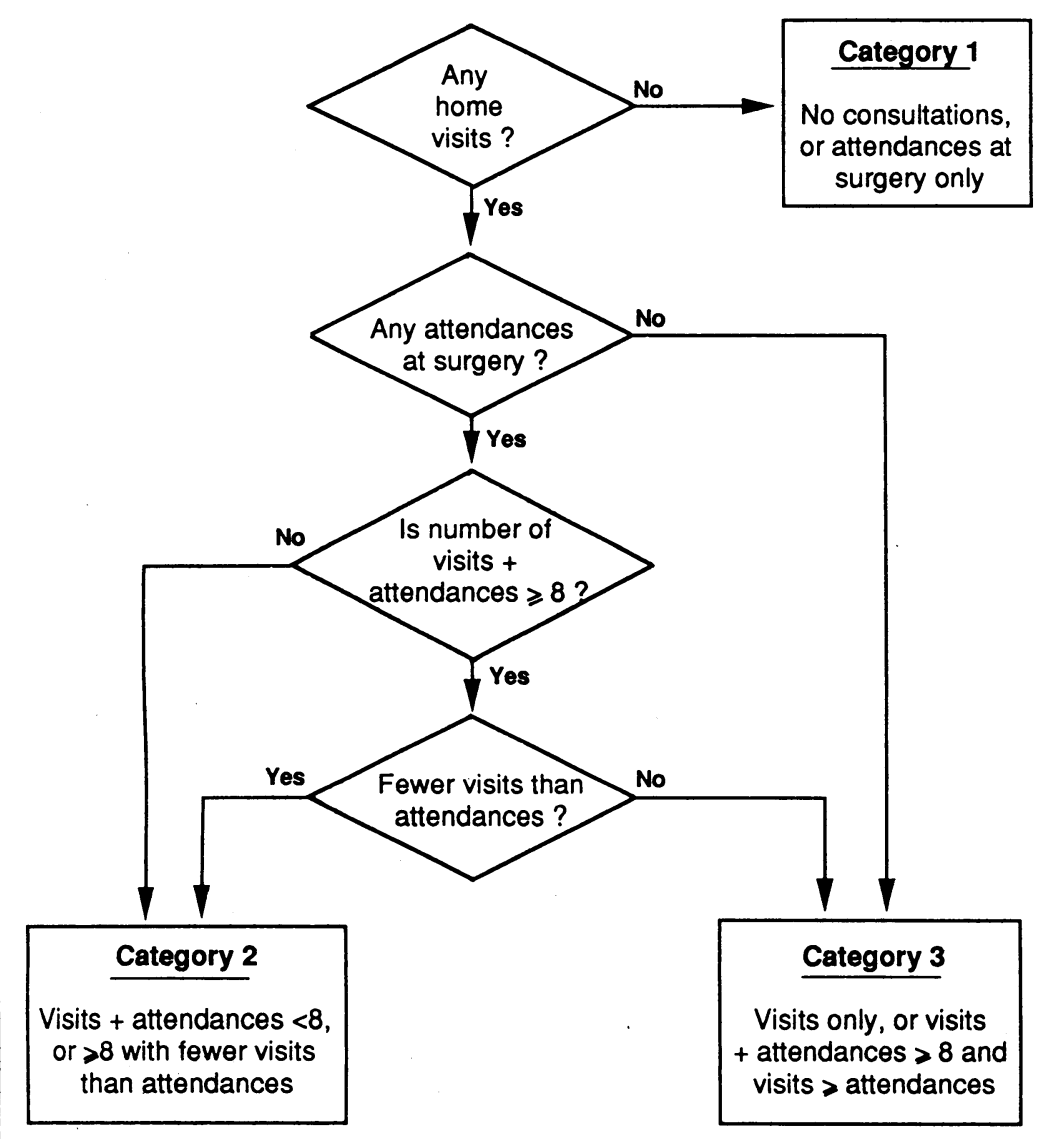

FIG 2-Consultation category based on consultations in previous two years

TABLE VI - Forecast (actual) percentages of patients with severe disability by sex, age, and to consultation category

\begin{tabular}{|c|c|c|c|c|c|c|c|c|}
\hline \multirow{3}{*}{$\begin{array}{c}\text { Age } \\
\text { (years) }\end{array}$} & \multicolumn{4}{|c|}{ Men } & \multicolumn{4}{|c|}{ Women } \\
\hline & \multicolumn{3}{|c|}{ Consultation category } & \multirow[b]{2}{*}{ Overall } & \multicolumn{3}{|c|}{ Consultation category } & \multirow[b]{2}{*}{ Overal } \\
\hline & 1 & 2 & 3 & & 1 & 2 & 3 & \\
\hline 75 & 3 & $7(12)$ & $28(25)$ & $6(5)$ & $5(4)$ & $10(9)$ & $36(40)$ & $10(10)$ \\
\hline 76 & 4 & $8(10)$ & 30 (20) & $6(5)$ & $5(2)$ & $11(8)$ & $38(41)$ & $11(10)$ \\
\hline 77 & $4(2)$ & $9(7)$ & $33(40)$ & 7 (7) & $6(4)$ & $12(10)$ & $40(44)$ & $13(13)$ \\
\hline 78 & 4 & $10(4)$ & $35(50)$ & 8 (11) & $6(4)$ & $13(11)$ & $43(51)$ & $15(16)$ \\
\hline 79 & 5 & 11 (5) & $37(47)$ & 10 (11) & 7 (4) & $14(10)$ & $45(53)$ & $17(18)$ \\
\hline 80 & 5 & $12(5)$ & $39(50)$ & 11 (11) & $8(7)$ & $15(11)$ & $48(46)$ & 19 (17) \\
\hline 81 & 6 & 13 (11) & $42(20)$ & $13(6)$ & $8(6)$ & 17 (16) & $50(41)$ & $22(17)$ \\
\hline 82 & 7 & $14(13)$ & $44(25)$ & $14(12)$ & 9 (5) & $18(17)$ & $53(50)$ & $24(21)$ \\
\hline 83 & 7 (4) & $15(25)$ & $47(30)$ & $16(14)$ & $10(6)$ & 20 (19) & $55(63)$ & $27(27)$ \\
\hline 84 & 8 & $16(33)$ & $49(30)$ & $19(17)$ & $11(6)$ & $21(16)$ & $58(61)$ & $30(34)$ \\
\hline 85 & 9 & $18(25)$ & $52(29)$ & $21(12)$ & 12 (13) & $23(25)$ & $60(59)$ & $34(39)$ \\
\hline 86 & 9 & 19 (17) & 54 & 24 & $13(18)$ & $25(25)$ & $62(59)$ & $37(40)$ \\
\hline 87 & 10 & 21 & 57 & 27 & $14(25)$ & $27(25)$ & $65(55)$ & $41(35)$ \\
\hline 88 & 11 & 22 & $59(50)$ & $30(17)$ & $15(20)$ & $29(24)$ & $67(63)$ & $44(39)$ \\
\hline 89 & $12(25)$ & 24 & $62(67)$ & $33(38)$ & $17(13)$ & $31(29)$ & $69(64)$ & $48(44)$ \\
\hline$\geqslant 90$ & 13 & $27(33)$ & $65(67)^{\circ}$ & $36(50)$ & 20 & $35(40)$ & $74(78)$ & $56(58)$ \\
\hline
\end{tabular}

relatively good health, which again confirms the results of other studies. ${ }^{5-7}$

Slightly over half the men and women who were housebound at interview had attended the surgery within the previous two years and had become housebound during this period. By grouping numbers of consultations in a simple way we divided the patients into three consultation categories based broadly on an increasing proportion of home visits in an increasing number of consultations (fig 2). These showed a highly significant trend towards greater disability (table V). Women again showed the stronger relation. Interestingly, the optimum discrimination between fit and housebound patients was found to be achieved by using the same category definitions for both sexes.

We used a statistical model to forecast the percentage of fit and housebound men and women in each of the three consultation categories at each age. The model accounted for $87 \%$ of the observed variation. The consultation category enabled the overall forecast for a certain age to be split into three quite different forecasts (table VI). As age and particularly consultation category increased the forecast percentage of housebound patients increased. Thus patients with a high consultation category and to a lesser extent advanced age are those with the greatest likelihood of severe disability.

These results lead to the possibility of identifying those patients most likely to be prone to severe disability from information contained wholly in their medical records. Brief scrutiny of the consultations over the past two years will quickly enable the patient's consultation category to be identified from figure 2 . Table VI then gives the forecast percentage of housebound patients for that sex, age, and consultation category. If that figure is greater than a chosen threshold the patient is deemed to merit further assessment. We chose a threshold of $10 \%$ as giving an acceptable compromise between sensitivity and specificity. With this threshold the following patients would have to be assessed: in consultation category 1 , men aged $\geqslant 88$ and women aged $\geqslant 84$; in consultation category 2 , men aged $\geqslant 79$ and women aged $\geqslant 76$; and in consultation category 3 , all patients. With our study sample we found that the $52 \%$ of all patients for whom the forecast percentage of housebound exceeded $10 \%$ included $90 \%$ of the housebound patients and excluded $74 \%$ of the fit patients. The $52 \%$ of the partially disabled patients who were also captured seemed likely to be mainly those most prone to severe disability, who thereby also merited further assessment.

When this scheme was tested, using the $10 \%$ threshold, by a survey of 94 patients aged 75 and over it correctly identified 36 of the $\mathbf{4 0}$ fit patients and six of the eight housebound patients. The two housebound patients not identified were an 81 year old man who had not consulted in the past year, who was described by the interviewer as "proud-refuses all help," and a 78 year old woman described by "I think she could get out of the house if she really wanted to." Inevitably, the occasional housebound patient who does not consult a general practitioner will slip through the net. In the original sample one of the 27 housebound men and six of the 116 housebound women had not consulted in the previous two and a quarter years.

We are using this scheme on a daily basis for all nonhousebound patients aged 75 and over who consult us. Almost invariably, elderly patients ostensibly consult about some specific ailment. Their general condition may go unregarded, particularly as doctors are reluctant to embark on detailed questioning about functional problems lest this awaken latent fears and lead to negative thinking. The scheme quickly gives us a pointer towards how closely to inquire into the patient's functional condition, living circumstances, and possible problems. For continuity the forecast can easily be updated and recorded at each consultation. We have found this useful, particularly with patients with whom we are unfamiliar.

The scheme does not require A4 records but merely an accurate record of consultations. It may be of interest to other practices, although the pattern of consultation will depend to some extent on the style of the practice as well as on the characteristics of its patients, so that details may require changing. For those practices that have yet to do a survey of their elderly patients the principles may help as a short cut to identifying most of those patients most prone to severe disability without the time, effort, and expense of interviewing or of a postal survey, which might receive an inadequate response. 
Secretary of State for Social Services. Promoting better health. London: HMSO, 1987:14.

Health Departments of Great Britain. General practice in the NHS. The 1990 contract. London: HMSO, 1989:20.

3 Williamson J, Stokoe IH, Gray S, et al. Old people at home: their unreported needs. Lancet 1964;i:1117-20

4 Stringfellow C, Elliott S, Stevens R, et al. Prevention for patients over 75-is it worth the bother? Br Med f 1986;292:1243-44.

Goldman L. Characteristics of patients aged over 75 not seen for one year in general practice. $\mathrm{Br}$ Med $\mathcal{F}$ 1984;288:645.

6 Ebrahim S, Hedley R, Sheldon M. Low levels of ill health among elderly nonconsulters in general practice. Br Med f 1984;289:1273-5.
7 Williams ES, Barley NH. Old people not known to the general practitioner low risk group. Br Med f 1985;291:251-4.

8 Anonymous. Keeping track of elderly patients. The "elderly at risk" register. London: King's Fund Centre, 1980. (80/198.

9 Tulloch AJ. Prevalence of disability observed in an Oxfordshire practice. fR Coll Gen Pract 1985;35:368-70.

10 Willis J. Simple scale for assessing level of dependency of patients in genera practice. Br Med f 1986;292:1639-40.

11 Armitage P, Berry G. Statistical methods in medical research. 2nd ed. Oxford: Blackwell Scientific Publications, 1987.

12 Central Statistical Office. Social trends No 16. London: HMSO, 1986:107-9.

(Accepted 26 fune 1990)

\section{MEDICINE AND THE MEDIA}

Leicestershire Health Authority Health Education Video Unit The Prevention and Early Detection of Cancer

\section{Preventing cancer $-\mathbf{a}$ DIY guide}

As European Cancer Year trundles manfully on, without the British press showing much enthusiasm, it would be interesting to know how many people are watching this very professional half hour video, produced for the public with the help of the European Commission (most of the scenes were clearly shot outside Britain).

Self examination is one of its messages. And it is not only European breasts and vulvas that are displayed for the benefit of our youth clubs, Rotary clubs, Women's Institutes, and elderly people's homes. Our fellow Europeans seem now to have thrown modesty to the winds to an even greater extent than we have. Penises and testicles fill the screen for long periods - often in close up, bold as brass, and in what used to be called glorious technicolor-their owners subjecting them to prolonged prodding, squeezing, weighing, and exploration of various kinds as they stand naked in their bathrooms performing their regular check ups and trying to remember how to find the epididymis. Even those who watch late night Channel 4 movies may get a bit of a shock. Perhaps in each village and hamlet the vicar should get a sneak preview and issue appropriate warnings to his flock before they see it.

Cervical smears are, of course, discussed (when is someone going to tell the media how doctors and nurses actually pronounce the word?). Also breast screening and the more recent campaign against exposure to the sun (especially the midday sun, which, according to Noel Coward, only mad dogs and Englishmen go out in anyway, at least in the tropics).

If cancer prevention gets going throughout Europe in the way that the producers of the video clearly wish, how much good will it really do? And how much harm? I think that many of us have mixed feelings. The first thing that has to be said, of course, is that as we have no choice but to date survival from diagnosis so called improved survival times are bound to follow earlier diagnosis whether or not treatment has really prolonged anyone's life. To be sure of benefit we need to see a reduction in mortality for the disease we are studying. And if overall mortality remains the same we should be suspicious of the accuracy of death certificates. Are we being as honest with the public about all this as we should be?

Next we have to weigh the advantage of tackling local disease at the earliest possible stage against the damage to peace of mind that the cancer label so often brings, no matter how favourable the prognosis. True, few things are worse for quality of life (mental as well as physical) than local cancer out of control; yet we must stick strictly to the true chances of this happening with different types of cancer.

Doubtless, now that ignorance is bliss and che sarà, sarà are both so out of fashion, all this self examination is, at least for some people, effective placebo treatment-giving everyone something to do and a feeling of being in control. Yet not only do we have to think of direct and indirect costs-taking money and staff away from other health needs-but we also have to balance the reassurance of a normal check up result with the anxiety that such checks often provokethe constant reminder of possible cancer, the agonising fear when there is a doubtful finding.

Andrew Sachs does the commentary in a voice so calm, so solid, and so reassuring that if he announced that most of us could expect to die of cancer before the century is out we would hardly bat an eyelid. What a versatile actor he is. Who would ever guess that this is Manuel of Fawlty Towers talking to us?

As to his script it is all too easy to criticise the efforts of others (certainly most of it is sound enough), but I would personally have preferred an occasional lighter touch - a little gentle humour to lessen fear and keep things in proportion. I would also like to have seen more stress on some of the more subtle and unpredictable aspects of cancer (for example, that it is often only hindsight that tells us who was in remission and who was cured). Anything to get away from the idea that it is all black or white-death sentence or cure.

For me the text is sometimes too bland and optimistic ("many of us can avoid cancer altogether . . . it seems likely that the best protection against cancer is a healthy lifestyle"); sometimes liable to mislead the public (as when "chemicals, radiation, and viruses" are said to be the main causes of cancer); sometimes too pessimistic (there is the usual excessive gloom about malignant melanoma - if it is so "extremely aggressive" why are 40 out of every 100 patients alive and well not five but 15 years after diagnosis - a far better outlook than that for several more common cancers?); and in one place badly wrong (those women whose cervical cancer is treated with "radiotherapy only," will think from what is said in this video that this means that the cancer has spread beyond the cervix).

Ten commandments for avoiding cancer must have seemed to the unknown European who dreamed it up a neat idea that would soon catch the public's imagination. But those who drafted the commandments (without Moses to help them) had to scrape the bottom of the barrel to get to 10 . Certainly there are not 10 for which there is good evidence that the number of people dying of common cancers would be appreciably reduced if they were obeyed. The evidence incriminating certain diets, for example, is still doubtful, and the British government still wisely refrains from offering any uncompromising warnings about diet (like that it gave about cigarettes 34 years ago-much to its credit because it stood to lose a lot of money if its advice had been immediately followed).

Personally I don't much fancy commandments (too bossy), but if we have to have them perhaps there should be just three: stop smoking, stop smoking, and stop smoking (yet this would be boring, because everyone knows it already). Perhaps the acid test is whether we practise what we preach. How many male doctors intend, for the rest of their lives, to give their scrotal contents a regular and systematic going over of the type described in such detail in this video? THURSTAN BREWIN, Bray, Berkshire 